\title{
EDITORIAL
}

\section{Disability, technology and e-learning: challenging conceptions}

Jane Seale*

University of Southampton, UK

\section{Introduction}

In considering the role that technology and e-learning can play in helping students access higher education and an effective learning experience, a large amount of the current research and practice literature focuses almost exclusively on accessibility legislation, guidelines and standards, and the rules contained within them (Abascal et al., 2004; Chisholm \& Brewer, 2005; Gunderson \& May, 2005; Paolucci, 2004; Reed et al., 2004; Slatin, 2005). One of the major problems of such an approach is that it has drawn higher education practitioners into thinking that their objective is to comply with rules. I argue that it is not (Seale, 2006). The objective should be to address the needs of students. The danger of only focusing on rules is that it can constrain thinking and therefore practice. We need to expand our thinking beyond that of how to comply with rules, towards how to meet the needs of students with disabilities, within the local contexts that students and practitioners are working. In thinking about how to meet the needs of students with disabilities, practitioners will need to develop their own tools. These tools might be user case studies, evaluation methodologies or conceptualizations:

The descriptions of what we know about current accessible e-learning practice are multilayered and complex. There may be value therefore in seeking to draw from these descriptions a conceptualization of accessible e-learning practice that: offers a simplified way of representing what we know about accessible e-learning; highlights what we know, what we don't know and what we need to know; offers new or different ways of thinking about accessible e-learning in the future. (Seale, 2006)

Using Wenger's notion of 'Communities of Practice' as a framework (Wenger, 1998), I argue that while the accessible e-learning community has tools and procedures (legislation, guidelines, standards, policies and automated evaluation tools), it lacks the complete and detailed concepts that are required for a coherent practice to emerge and develop (Seale 2004, 2006). In addressing issues of disability, technology and e-

\footnotetext{
*School of Education, University of Southampton, Highfield, Southampton SO17 1BJ, UK. Email: J.K.Seale@soton.ac.uk
} 


\section{Editorial}

learning in higher education, the contributors to this issue challenge us to conceptualize or re-conceptualize our understanding of:

- assistive technology;

- best accessibility practice; and

- taking responsibility for accessibility.

\section{Re-conceptualizing assistive technology}

Geraldine Price offers the metaphor of assistive technology as a 'scaffold' that guides and facilitates participation. Through the use of three in-depth student case studies Price also demonstrates how assistive technology does not have to be specialized or complex to be useful. Sometimes, simple solutions or features of standard packages can be very effective in supporting the needs of students with disabilities. This is particularly important given that many who work in student support services are beginning to realize that students need a significant amount of training and support to use their technological equipment, particularly complex equipment (Downie, 2000; Haines \& Molenaar, 2000; Keller et al., 2000; Henderson, 2002; Sajka \& Roeder, 2002).

As E. A. Draffan and Peter Rainger argue:

Assistive technologies have a learning curve and it is essential to ensure adequate training time is provided and that the training is provided in the context of the students' own learning and course requirements.

Draffan and Rainger also argue against a conceptualization (categorization) of assistive technologies that focuses solely on the disability of the user and fails to take into account their skills, abilities and preferences.

Mike Wald explores how Automatic Speech Recognition can be re-conceptualized as a technology that can assist with receptive as well as expressive communication, while David Sloan and colleagues challenge our understanding of assistive technology by arguing that multimedia can be viewed as an assistive technology for people with a range of needs:

For all these groups, arguably the most inaccessible way of presenting information is through a long page of on-screen text. It follows that presenting information in alternative ways - pictures, diagrams, animated diagrams, video clips, audio recordings - is far more effective in conveying information and experiences, and hence supporting comprehension and retention of information. Multimedia thus becomes an accessibility solution - an assistive technology.

\section{Conceptions of best 'accessibility' practice}

The contributions in this issue conceptualize best 'accessibility' practice in a number of ways. Best practice is conceptualized as:

- focusing on learning;

- flexible, adaptable and proactive; and

- holistic. 


\section{Best practice focuses on learning}

For many of the contributors, best practice involves not focusing solely on the technical aspects of accessibility (e.g. accessibility guidelines), but also taking into account the context in which users are trying to access online materials and resources: the context of learning. Some contributors go further than this and argue that best practice takes the focus away from a learner's disability or from e-learning. For example, Draffan and Rainger present a model for the identification of challenges to blended learning for students. In doing so they argue against approaches that focus on remediating the perceived 'problems' that students with disabilities have:

The model proposed, provides a starting point for the identification of challenges to learning from a socio-cultural perspective rather than a medical or rehabilitation perspective. This holistic perspective is key to moving 'thinking' towards a more inclusive learning approach that embraces the needs of all learners such as those for whom English is a Second or Other Language (ESOL) regardless of a defined disability.

Similarly, Lawrie Phipps and Brian Kelly argue that there is a need to provide accessible learning experiences, and not necessarily accessible e-learning experiences.

\section{Best practice is flexible, adaptable and proactive}

The contributors conceive of flexibility in slightly different ways and contexts. For example, in discussing how dyslexic students use technology and software to support their learning, Price argues that it is the flexibility of use that makes the difference for them and therefore that 'individualization is the key to success'; while Sloan and colleagues address flexibility in the context of the application of accessibility guidelines and argue that checklists are not sufficient:

This approach acknowledges arguments that, given the varying nature of accessibility requirements amongst individuals with specific impairment or combination of impairments, combined with the unique aims and context of an online resource-such as audience characteristics and usage environment, a guideline-based approach is not sufficient to ensure the most appropriate accessibility solutions are provided.

The Skills for Access project described by Sloan and colleagues therefore tried to avoid giving checklist style guidelines in order to encourage designers and developers to thinking more widely about accessibility issues. This caused discomfort for some users, however, who expressed a preference for 'short check-list style information'.

Steve Green and colleagues challenge us to think about the extent to which best practice can be captured in a single standard and in doing so develop an argument for adaptability:

There is a new recognition that addressing all issues of accessibility, multiculturalism and language in a single standard could never be realised: one group or other would inevitably be excluded. However, we argue that the idea that resources should be adaptable (and adapted) to the needs of individuals or groups is eminently sensible.

Many of those arguing for a flexible, adaptable approach to accessibility position themselves as arguing against approaches to universal design (as described by Sheryl 
Burgstahler). This is because central to the universal design approach is a commitment to the principle that products should not have to be modified or adapted. They should be accessible through easily imposed modifications that are available 'right out of the box' (Jacko \& Hanson, 2002, p. 1). While some purists argue that universal design is about designing for everyone, the majority of proponents agree that designing for the majority of people is a more realistic approach (Bohman, 2003; Witt \& McDermott, 2004). For example, Vanderheiden argues that:

There are NO universal designs; there are NO universally designed products. Universal design is a process, which yields products (devices, environments, systems, and processes), which are usable by and useful to the widest possible range of people. It is not possible, however, to create a product, which is usable by everyone or under all circumstances. (1996)

It would therefore appear reasonable to assume that adaptable design approaches can live alongside universal design approaches.

The contributors also have slightly different perspectives on how best practice might be proactive. For Wald, Automatic Speech Recognition enables academic staff to take a proactive rather than a reactive approach to teaching students with disabilities by providing practical, economic methods to make their teaching accessible and assist learners to manage and search online digital multimedia resources. Sloan and colleagues argue that the holistic approach is proactive in that it enables educators to anticipate student needs. Burgstahler, meanwhile, argues that:

Being both proactive (by applying universal design principles) and reactive (by providing accommodations) in offering courses results in more inclusive programs and minimizes the need for accommodations for specific students.

\section{Best practice is holistic}

The arguments presented in Phipps and Kelly's model of a holistic approach to accessible e-learning are reflected by many of the contributors in this issue. For example, Sloan and colleagues argue for a holistic approach that ensures the accessibility solutions chosen are appropriate for the context in which the resource will be used. Several of the contributors concur with Phipps and Kelly that approaches to addressing accessibility should not focus solely on technical issues but should focus also on learning issues. For example, Draffan and Rainger argue that in order ensure inclusive and accessible learning experiences, the full spectrum of learner characteristics must be taken into account. Martyn Cooper argues for the fundamental importance of learning objectives in establishing accessibility criteria and in identifying and making adjustments to online course components to meet the needs of disabled students:

So often in accessibility considerations of educational web sites or software, the focus is on how best to make a particular element technically accessible to disabled students. However, the author maintains that educators need to stand back from these considerations and remember that fundamentally what we are seeking to make accessible is the learning. This may seem an obvious statement, but it is often missed, and is key to deciding what is the most appropriate response to meet the needs of disabled students. Thus, fundamental to 
accessibility considerations in online education is having clearly established learning objectives.

While the contributors challenge us to think about 'best practice', there are some researchers who argue that focusing solely on 'best practice' is not helpful. For example, Konur (2000) argues that in order to end discrimination we need to develop an 'evidence-based' model rather than a 'good practice' model. By this, Konur means that we should move away from just focusing on positive outcomes of disability initiatives (good practice culture) and towards recording everything that is happening, particularly the bad practice (evidence-based culture). Formal, publicly available evidence of bad-practice in relation to e-learning accessibility is virtually non-existent however. Although there are a number of studies that have evaluated the accessibility of university main websites, there is very little evaluative data regarding the student experience of e-learning in its most broadest sense (beyond access to websites and Virtual Learning Environments). A small amount of unevaluated evidence exists on learning and teaching project websites specialist mailing lists and in the occasional news reports (for example, Parkin, 2001; Tierney, 2002). This perhaps presents an additional challenge to disability and accessibility researchers and practitioners.

\section{Conceptions of responsibility}

In describing current and future practice, the contributors challenge us to think about responsibility for accessibility in terms of:

- Where in the design process accessibility should be addressed?

- Who should take responsibility: individuals or institutions?

- Whether responsibility should be predominantly shouldered by specialists or experts (at an individual or service level) or shared amongst all.

In considering where in the design process accessibility should be addressed Sloan and colleagues argue that those who commission multimedia are responsible for including accessibility in the design specification:

The most appropriate and effective place to author and combine accessibility features is at the point of production, but the provision of accessibility features is not commonly considered a standard part of media production, and may require a specific request at the time of commissioning.

Cooper and Burgstahler address responsibility at an institutional or programme level, and in doing so consider the roles of individuals within the institution or programme. Cooper describes how the Open University in the United Kingdom has addressed accessibility issues and how responsibility is divided and shared between different teams/sections of the institution. Burgstahler describes how she and her colleagues have attempted to evaluate the extent to which distance learning programmes in the United States are taking responsibility for accessibility. She reports some difficulties in identifying exactly which staff had a responsibility for accessibility: 


\section{Editorial}

Sometimes, several distance learning staff members were consulted before the correct person who could make specific programmatic changes was consulted and this person was not the same for each Indicator.

Uncertainty about roles and responsibilities coupled with a lack of clear leadership can slow down the time it takes for staff to 'buy in' to accessibility and change their practices.

Cooper also highlights the importance of not devolving primary responsibility to specialist units (e.g. disability advisors); rather, the responsibility of specialist units is to support the work of others (e.g. course teams). There is a growing recognition that such an approach is more inclusive and less likely to lead to students with disabilities being seen as a 'special' group that need to be dealt with by special isolated, or segregated services (Edwards, 2000; Shaw, 2003; Tinklin et al., 2004). Seale (2006) argues that adopting a model whereby specialist disability staff are encouraged to support other staff in the institution could pave the way for important strategic partnerships to develop. For example:

- lecturers can liaise with assistive technologists and disability officers regarding the kinds of e-learning experiences that they are offering in their courses, so that assistive technologists and disability officers can make more informed reccomendations to students about the kind of support and specialist technologies they will require in order to engage with the e-learning on offer; and

- disability officers can be involved in embedding accessibility policies and practices into the wider community, and ensuring that disability is integrated into an institution's planning and funding programme.

\section{Conclusions}

The different conceptions offered by the contributors to this issue are extremely useful in that they prompt us to think about barriers to learning for students with disability (e.g. rigid application of guidelines) and explore how changes or adaptations to cultures, policies or approaches might reduce these barriers. Such exploration may help to structure future discussion and debate regarding disability, technology and accessibility in higher education.

\section{References}

Abascal, J., Arrue, M., Fajardo, I., Garay, N. \& Tomas, J. (2004) The use of guidelines to automatically verify Web Accessibility, Universal Access in the Information Society, 3, 71-79.

Bohman, P. (2003) Introduction to web accessibility. Available online at: http://www.webaim.org/ intro/ (accessed 5 October 2005).

Chisholm, W. \& Brewer, J. (2005) Web content accessibility guidelines 2.0: transitioning your website, paper presented at CSUN '05, Los Angeles, 17-19 March 2005. Available online at: http://www.csun.edu/cod/conf/2005/proceedings/2355.htm (accessed 5 October 2005).

Downie, A. (2000) The microchip revolution improving opportunities for students who have disabilities, paper presented at Pathways 5 Conference, Canberra, Australia, 6-8 December 
2000. Available online at: http://www.canberra.edu.au/pathways/papers/downie.pdf (accessed 10 March 2005).

Edwards, M. (2000) Wising up: strategies for moving towards an inclusive model of service provision for higher education students with disabilities, paper presented at Pathways 5 Conference, Canberra, Australia, 6-8 December 2000.

Gunderson, J. \& May, M. (2005) W3C user agent accessibility guidelines test suite version 2.0 and implementation report, paper presented at CSUN '05, Los Angeles, 17-19 March 2005. Available online at: http://ww.csun.edu/cod/conf/2005/proceedings/2363.htm (accessed 5 October 2005).

Haines, A. \& Molenaar, S. (2000) Breaking down the barriers: a team approach to learning development, paper presented at the Pathways 5 Conference, Canberra, Australia, 6-8 December 2000. Available online at: http://www.canberra.edu.au/pathways/papers/haines.pdf (accessed 10 March 2005).

Henderson, P. (2002) Physical disability and technology, in: L. Phipps, A. Sutherland \& J. Seale (Eds) Access all areas: disability, technology and learning (ALT/JISC/TechDis), 29-32.

Jacko, J. A. \& Hanson, V. L. (2002) Universal access and inclusion in design, Universal Access to the Information Society, 2, 1-2.

Keller, S., Owens, J. \& Parker, C. (2000) Improving online access for people with disabilities, paper presented at 8th European Conference on Information Systems (ECIS2000), Vienna, Austria, July 2000. Available online at: http:/www.deakin.edu.au/buslaw/infosys/docs/workingpapers/archive/Working_Papers_2000/2000_19_Keller.pdf (accessed 5 October 2005).

Konur, O. (2000) Creating enforceable civil rights for disabled students in higher education: an institutional theory perspective, Disability \& Society, 15(7), 1041-1063.

Paolucci, P. (2004) Should online course design meet accessibility standards?, Educational Technology E Society, 7(1), 6-11.

Parkin, J. (2001) Exams and DSA for DB. Message posed to the Deaflink JISC Mailing list. Available online at: http://www.jiscmail.ac.uk/cgi-bin/webadmin?A2=ind01\&L=deaflink $\& \mathrm{~T}=0 \& \mathrm{~F}=\& \mathrm{~S}=\& \mathrm{P}=477$ (accessed 5 October 2005).

Reed, P. S., Gardner-Bonneau, D. \& Isensee, S. (2004) Software accessibility standards and guidelines: progress, current status and future developments, Universal Access to the Information Society, 3, 30-37.

Sajka, J. \& Roeder, J. (2002) PDF and public documents: a white paper (American Foundation for the Blind). Available online at: http://www.afb.org/section.asp?Documentid=1706 (accessed 10 March 2005).

Seale, J. (2004) The development of accessibility practices in e-learning: an exploration of communities of practice, Association for Learning Technology fournal, 12(1), 51-63.

Seale, J (2006) Disability and e-learning in higher education: accessibility research and practice (Oxford, Routledge).

Shaw, J. (2003) Bedding down for the long haul-philosophy of service delivery for students who have a disability or a chronic medical condition. Available online at: http://www.eophea.anu.edu.au/ Jenny\%20Shaw2003.pdf (accessed 5 October 2005).

Slatin, J. M. (2005) Overview of the general techniques for web content accessibility guidelines 2.0, paper presented at CSUN '05, Los Angeles, 17-19 March 2005. Available online at: http://www.csun.edu/cod/conf/2005/proceedings/2382.htm (accessed 5 October 2005).

Tierney, J. (2002) University students take complaints to Anti-Discrimination Commissioner. Australian Broadcasting Corporation, TV Program Transcript. Available online at: http:// www.abc.net.au/7.30/content/2002/s460046.htm (accessed 5 October 2005).

Tinklin, T., Riddell, S. \& Wilson, A. (2004) Policy and provision for disabled students in higher education in Scotland and England: the current state of play, Studies in Higher Education, 29(5), 637-657.

Vanderheiden, G. (1996) Universal design. What it is and what it isn't. Available online at: http:// trace.wisc.edu/docs/whats_ud/whats_ud.htm (accessed 5 October 2005). 


\section{Editorial}

Wenger, E. (1998) Communities of practice: learning, meaning and identity (Cambridge, Cambridge University Press).

Witt, N. \& McDermott, A. (2004) Web site accessibility: what logo will we use today?, British fournal of Educational Technology, 35(1), 45-56. 